\title{
Assessing management models for off-grid renewable energy electrification projects using the Human Development approach: case study in Peru.
}

\author{
Pau Lilloa,b*, Laia Ferrer-Martíc, Alejandra Bonid, Álvaro Fernández- \\ Baldore
}

${ }^{a}$ Local Development and International Cooperation programme, Universitat Politècnica de València, Camino de Vera s/n, Valencia, Spain,

${ }^{\mathrm{b}}$ Engineering Without Borders, C/ Murcia, 24, Barcelona, Spain

' Department of Mechanical Engineering, Universitat Politècnica de Catalunya, Av. Diagonal 647, Barcelona, Spain

d INGENIO, Universitat Politècnica de València, Camino de Vera s/n, Valencia, Spain

e Universitat Politècnica de València, Camino de Vera s/n, Valencia, Spain

Corresponding author (*): palilrod@upvnet.upv.es, 0034686041097

Laia Ferrer-Martí: laia.ferrer@upc.edu

Alejandra Boni: aboni@dpi.upv.es

Álvaro Fernández-Baldor: alferma2@upvnet.upv.es 


\begin{abstract}
Electrification systems based on renewable energy have proven to be suitable for providing electricity autonomously to rural communities and thus reducing poverty. When implementing these systems, a management model is usually designed to maximise technical and financial sustainability. To improve the design and performance of systems, different evaluations of management models have been made that usually centre on products and final utilities. However, this excessively utilitarian vision of development restricts an analysis of the impact that these projects may have on people's lives. To overcome these limitations, we have used the Human Development approach to evaluate the management model of five electrification projects that use different technologies in Cajamarca (Peru). With this approach, the base of information is enhanced, which enables a broader assessment of various key dimensions of development that should be considered in the management model to improve the impact of such projects. The results show the weaknesses of the design and implementation process of the management model. Several ideas are proposed to avoid these weaknesses and to maximise the chance of success.
\end{abstract}

\title{
Keywords
}

Off-grid rural electrification

Management model

Human development approach

\section{Introduction}

Access to electricity is considered to be a key factor in reducing poverty, especially in rural areas, where development indices are usually low (for example, Gomez et al., 2010; Pasternak, 2000; Borges et al., 2007; Kooijman-van Dijk and Clancy, 2010; Valer et al., 2014; Nerini et al., 2014; Shyu, 2014; Groh, 2014). As in most countries (Bhattacharyya, 2012), the Peruvian government's current strategy to increase rural electrification is oriented towards the expansion of the national grid. However, the degree of isolation of non-electrified rural communities represents a significant barrier to access to this service due to higher investment costs, limited capacities of operation and maintenance (Palit, 2013) due to a lack of education and access to information (ESMAP, 2001), and low consumption rates (Gouvello, 2002). Isolation is particularly prevalent in Peru because its varied and complicated geography includes a wide mountain range and vast areas of rainforest.

In such contexts, small stand-alone systems for energy generation, especially renewable energy (RE) based systems, represent a suitable alternative for providing electricity to the rural population (Nguyen, 2007; Breyer et al., 2009; Benecke, 2008; Chaurey, 2004; Lhendup, 2008). Studies show that the following are some of the advantages of decentralised models: the use of local resources and the avoidance of costly and inefficient transmission losses (Benecke, 2008), suitability for low- 
load factor projects (Kaundinya et al., 2009), independence from fuel supply and respect for the environment (Nguyen, 2007), and the provision of energy independence for users (Hiremath et al., 2009; Akorede, 2010). In addition, these systems can be managed locally, enabling the generation of local jobs and the participation of local people in decision making (Sánchez, 2006). In particular, ESMAP (2001) states that "although it is true that all aspects (legal framework, finance, technology, and so forth) are important for improving the rural population's access to electricity, the continuity of the service (that is, the system's sustainability) can only be assured if its management models are functional and efficient".

In this article, we analyse microenterprise management models focusing on factors that are not usually analysed or that were considered to a lesser extent in previous evaluations. In particular, we use the Human Development (HD) approach, which enables us to extend the analysis on various key dimensions of development that should be considered in the process of implementing a management model. Thus, the base of information (Sen, 1999) used to assess the impacts of such projects and improve the planning is enhanced to maximise the chances of future success.

In particular, we focus on an analysis from the HD approach of the microenterprise management model for stand-alone rural electrification systems with RE developed by the Non-Governmental Organisation (NGO) Practical Action (PA) in the northern Peruvian Andes that is specially designed to promote the development of poor rural communities. The analysis has been conducted in the region of Cajamarca, in the northern Peruvian Andes. Five RE electrification projects in isolated rural communities implemented by PA have been studied, whose management model of these projects will be described in detail.

The paper is structured as follows. Section 2 describes how management models have been analysed by other authors and the management model of PA. Section 3 describes the methodology used. Section 4 presents the results obtained. Section 5 discusses the results and makes recommendations based on the HD approach. Finally, Section 6 highlights the conclusions of the investigation.

\section{Management models of isolated rural electrification projects}

\section{$2.1 \quad$ Literature overview}

There are numerous management models of stand-alone electrification systems, among which the most common are those managed privately, cooperatively, or by state or local municipalities or communities. These models have different characteristics in terms of ownership of the systems, level of user participation, responsibility for operation and maintenance of systems, user involvement in infrastructure construction and installation of equipment, management of tariff payments, etc. (ESMAP, 2001). 
Given the importance of management models in stand-alone rural electrification projects with RE, various studies have analysed them, including that designed by PA. ESMAP (2001) analysed management types based on whether the system is owned by the state, municipality, the community, or cooperative or private interests in 12 communities in Peru, evaluating the service quality and economic aspects of each system. Yadoo and Cruickshank (2010) analysed cooperatives as a management model in USA, Bangladesh, and Nepal, focusing on their technical and economic feasibility and sustainability while also considering the effect of public participation and the promotion of equity and empowerment that such a model can create.

Regarding PA's management model, Sanchez et al. (2006) performed a comparison between governmental, municipal, private, and community management models in Peru. He focused on technical and economic sustainability, concluding that the most successful is the microenterprise model implemented by PA. Ferrer-Martí et al. (2012) studied three projects in the Peruvian Andes using the microenterprise management model employed by PA, taking into account the benefits of the projects in terms of new resources or services, as well as the technical and economic sustainability of the systems, and concluded that the management model is generally satisfactory in the three communities. Yadoo and Cruickshank (2012) analysed three projects in Peru, Nepal, and Kenya with different management models. The organisational dimension, capacity strengthening, client relationships, and stakeholder participation were evaluated. In this analysis, the project implemented by PA was the highest rated in the social and institutional dimensions.

However, there might be limitations on the different management models analysed that have escaped the attention of the authors of previous studies due to the use of an approach excessively centred on technical and economic aspects, without addressing in depth the impact these projects have on people's lives beyond the provision of material and economic resources. As we will highlight further, by using the HD approach, it is possible to identify, analyse, and propose strategies to substantially improve the impact of this type of intervention regarding development promotion.

\subsection{Description of the Practical Action Management Model}

The analysed management model was designed and promoted by PA, which is an international technical cooperation NGO that has been operating in Latin America since 1985. PA has developed a management model (Ferrer-Martí et al., 2010; 2012) whose main objective is the efficient financial and technical long-term operation of small isolated power systems. In this management model, the owners of the systems (generally the district municipality) give responsibility for operation, maintenance, and administration to a private local microenterprise (managed locally by the members of the community) on a medium or long-term contract.

The management model is composed of different actors, including the microenterprise, users, and the municipality (Ferrer-Martí et al., 2012). 
- Users and control unit: Each user is required to pay a monthly tariff that covers the maintenance of the equipment and has the right to attend monthly financial review assemblies. Furthermore, the community periodically evaluates the performance of the microenterprise and either re-elects the current operator-administrator or appoints a new person to run it. Moreover, a control unit elected by the assembly and composed of local people, mainly authorities, is responsible for overseeing the administration of the microenterprise (use of tariffs, non-paying clients, quality of service, etc.) to ensure compliance of user obligations and address their complaints or suggestions.

- Microenterprise: The microenterprise is composed of one or more of the residents of the community. In each community, there is usually an operator and an administrator who are responsible for operation, preventive and corrective maintenance, and the collection of monthly tariffs. This tariff provides a reserve fund, which is deposited in a bank account, and gives the microenterprise a monthly sum to replace equipment when it reaches the end of its operational life.

- Municipality: The legal owners of the systems are the municipalities. The municipality signs a concession contract assigning the service management to the microenterprise; thus, it cannot interfere with day-to-day operations. However, as the legal owner, the municipality shares responsibility for replacing equipment when needed, so it must add to the community reserve fund if this reserve is insufficient, reinforcing the sustainability of the system without reducing users' responsibility.

\section{PLEASE INSERT FIGURE 1}

Figure 1. General scheme of the Practical Action management model. Adapted from Ferrer-Martí et al. 2010.

The design and implementation of the management model is performed in parallel to the development of the project, from identification to implementation. Below, we present the activities relating to the management model that are developed at the different stages of the rural electrification project:

- Initial phase. Identification and design: First, the community and the type of electrification project that could be developed are identified with a socioeconomic and local resource availability analysis predominantly based on quantitative information. Strong emphasis is put in this phase, as the lack of these data can result in errors when determining household energy needs, and thus minimizing users' satisfaction levels (Shyu, 2013). PA usually prioritises those projects that have been demanded by the communities themselves to ensure higher levels of motivation by the population. However, PA sometimes proposes the implementation of a rural electrification project to communities.

Once the project is defined, PA begins the technical design in parallel with the design of 
the management model. Although the base of the management model is almost standardised, some details must be defined depending on the technology and socioeconomic characteristics of the community. In particular, the composition of the microenterprise and the type of tariff must be determined. In the latter case, PA makes an initial proposal based on an analysis of each family's expenses for candles, batteries, kerosene, etc. The tariff must be lower than this expenditure to ensure that users can pay. Once the proposal is launched, the assembled population decides whether the proposal is appropriate and may propose an alternative, which must be approved by the PA technical team.

- Development phase. Installation and training: In this phase, the operator and administrator of the microenterprise are selected and trained to take over operation and maintenance. First, the community itself nominates candidates for these posts, who participate in a comprehensive training program that covers both administrative and technical skills and usually takes place in the CEDECAP (Demonstration and Training Centre in Appropriate Technologies) in Cajamarca (Escobar et al., 2012) or in a close community with a similar electrification project, allowing operators/administrators to share their experiences with future operators/administrators. At the end of this training program, community leaders and PA technicians select the best candidates based on test scores and other criteria, such as community involvement and reputation.

In addition, users receive training on the efficient use of energy, maintenance tasks, basic operation of equipment, the management model, the tariff scheme, fines for nonpayment, etc. The theoretical lessons normally take place at the school, and hands-on practice is undertaken during the systems installation. Involvement and collaboration by the entire community in the construction of infrastructure and installation of the systems are specially promoted so that villagers' identification with the systems will increase (Drinkwaard et al., 2010).

- Operational phase. Technical maintenance and financial management: Once the systems are in operation and the capacities of the population to perform technical maintenance and financial management have been strengthened, power is made available. Monthly monitoring and decision-making community meetings are set up, relying on the involvement of the control unit to ensure proper operation of the systems and management model.

\section{Methodology}

In this paper, we have used the four pillars of the HD approach described below as the base of 
information for evaluating the management model in five stand-alone electrification projects in rural communities in Cajamarca implemented by PA. These communities use the management model described in Section 2.2, with financial support from the respective district municipalities. To enhance the analysis, we selected communities close to each other, with similar socioeconomic and cultural characteristics but different energy systems; thus, we minimise the bias that an analysis of projects using only one type of technology might contain.

\subsection{The Human Development approach as a framework for the analysis of technological projects}

The HD approach is a very appropriate framework for conceptualising technological interventions because it provides a more extensive and complete vision of the development processes. The basic purpose of HD is to increase people's opportunities, as opposed to simply promoting economic growth or improving the living conditions of the population.

The HD approach is based on four fundamental pillars that must support any strategic development action to achieve what we mean by success: expanding opportunities for people and transforming them into agents of their own development (ul Haq, 1995). These four principles are as follows:

- Equity and diversity: People should enjoy equal access to opportunities, and their diversity must be recognised. Developing inequity means restricting the choices of individuals in a society. According ul Haq (1995), in many cases, equitable access to opportunities requires a fundamental restructuring of the establishment.

- Sustainability: What HD means by sustainability should not be understood as the indefinite preservation of resources but rather as the preservation of the same level of welfare for future generations. This understanding of sustainability refers not only to environmental sustainability but also to something wider, namely, the sustainability of human, physical, and financial capital.

- Empowerment: People are not understood as objects but as subjects of development and should be able to freely make decisions that affect their lives, which implies economic liberalisation, avoiding excessive economic controls and regulations; decentralisation of power so that governance rests with each person; and full participation of the population in the elaboration and implementation of decisions.

- Productivity: Economic growth is also critical for HD, so an environment where people can be productive through the creation of sustainable livelihoods is necessary. However, it must be remembered that people are not only the means but also the ends of development, so productivity should be treated only as one aspect of HD, with the same level of importance as the other three. 
In the field of technology, there are several authors who emphasise the usefulness of the HD approach in the design and planning of technological projects. Dong (2008) argues that, from a social justice perspective, one should pay attention to the capacity of citizens to design and play an active role in the transformation of their lives. Similarly, Oosterlaken (2009) proposed that technical designs are very important because of their impact in terms of HD. Gomez and Silveira (2010) analyse the process of rural electrification in the Brazilian Amazon, in which the Human Development Index is used to prioritise and analyse the impact of rural electrification projects. The authors conclude that the HD approach is appropriate in this type of projects.

Moreover, in the analysis of specific projects, Oosterlaken et al. (2012) analyse a project of podcasting devices for farmers in Zimbabwe and find the key to success for the project was an attention to the diversity of users and their participation in the project. In the field of RE, Fernández-Baldor et al. (2012) compare three microhydro rural electrification projects in Guatemala and Bolivia. The results varied based on the different levels of user participation; despite using the same technology and a similar management system, satisfactory results were only obtained in the project in which the community was involved and motivated from the beginning.

\subsection{Description of the case studies}

The analysis is based on 5 projects that use different technologies: microhydro power plants, PV systems, wind generators and hybrid systems in individual or microgrid distribution systems. The energy source and distribution options implemented in each project depend on the available resources and the structure of the community. In general, when water resource is sufficient, PA always considers the microhydro power as the first option, since these systems are usually the lowest cost option for off-grid rural electrification (Coello et al., 2006; Kaygusuz, 2011; REN21, 2008; Williams and Simpson, 2009), are reliable for off-grid systems (van Els et al., 2012), and the energy is continuously available (Drinkwaard et al., 2010), . If water resource is not available, photovoltaic (PV) or wind systems are used, depending on resource availability, as their suitable to provide decentralized electrical service to rural households (Bugaje, 2006; Jacobson, 2007; Hiremath, 2009; Chaurey and Kandpal, 2010a, 2010b; Ferrer-Martí et al., 2012; Valer et al., 2014). Regarding the choice between individual or collective systems, it must be noted that stand-alone systems usually have low capacity factor, high battery costs and limited capacity to store energy (Khan and Iqbal, 2005; Kaundinya, 2009). For that reason, if houses are close to each other, thus reducing the cost of the microgrid infrastructure, it is technically and often economically advantageous to install microgrids instead of individual systems to reduce the impacts of these inconveniences. However, if houses are far from each other the cost of the microgrid can be much higher than individual systems, thus limiting the economic feasibility of this alternative.

The characteristics of the five studied projects are briefly detailed below:

- Alto Perú: A community with 51 families. Due to the high level of dispersion between 
households in this community and the variability of available energy resources, different electrification systems were installed in different areas. First, a microhydro power plant was installed to serve four households and the school, which were located close to each other and near to the only small waterfall in the community. Second, in the upper area of the community, where wind resource is high and houses are located close to each other, a wind microgrid fed by locally manufactured wind turbines was installed (Leary et al., 2012). Third, 40 households located in the lower area of the community, where there is no water resource available, wind is scarce, and there is a huge dispersion rate, were electrified with individual solar photovoltaic systems. Finally, a PV microgrid for four families, and a health centre and a restaurant, which were located close to each other in an area with no wind or water resource, was constructed. All the systems operate on AC, and there are three operators and one administrator for all the systems. The monthly tariff that each user must pay depends on consumption, with a baseline of 13 Nuevos Soles (NS). ${ }^{1}$ The tariff becomes cheaper (per unit) with higher consumption to encourage small businesses (decreasing block tariff).

- Suro Antivo: A community with 60 families. Since water resource was abundant in this community, a microhydro power plant was installed to provide electricity for households and the school. The project was executed in two phases, with 45 households electrified first, followed by the remaining 15 . All the systems operate on AC, and there are two operators who alternate monthly and an administrator. The monthly tariff that each user must pay depends on consumption, with a baseline of 10 NS (decreasing block tariff).

- Chorro Blanco: This community, which also has sufficient water resource, has 37 families electrified with a microhydro system. All systems operate on AC, and there is one operator and one administrator. The monthly tariff that each user must pay depends on consumption, with a baseline of 10 NS (decreasing block tariff).

- Campo Alegre: In this community, where no water resource was identified and houses are located far from each other, individual hybrid PV-wind systems were installed in 20 households. The combination of these two technologies was defined to provide a more reliable service than a one single technology system (Bhattacharyya, 2012; Hiremath et al., 2009). All systems operate on DC, and there is one operator and one administrator. The monthly tariff that each user must pay has a flat rate of 14 NS.

- El Regalado: Since water resource was sufficient in this community, a microhydro system was installed to provide 31 families with access to electricity. All systems operate on AC, and there is one operator and one administrator. The monthly tariff that each user must pay depends on consumption, with a baseline of 10 NS (decreasing block tariff).

\footnotetext{
${ }^{1}$ Exchange rate one dollar/Nuevo Sol is approximately 2.60 .
} 


\section{PLEASE INSERT TABLE 1}

\section{Table 1. Comparison of analysed projects}

Note that as beneficiaries, we have included both the owners of the house as well as 'mitayos' (families who live in the house of their employer to look after livestock and land in exchange for a salary when the owners migrate to the city).

\subsection{Field methodology}

To perform an evaluation using the HD approach, we considered it appropriate to mainly collect qualitative information by means of participatory techniques. The qualitative paradigm has the advantage of introducing the analyst to the phenomenological complexity of the world, with all its connections, correlations, and causes. Moreover, according to Cook et al. (2005), qualitative and participatory methods should be used to help gain insight on energy projects. For these reasons, the methodology used in the field work is based on semi-structured interviews, focus groups, participatory workshops, and participant observation. It should be noted that we have sought to obtain information from multiple actors using various techniques to properly triangulate our findings and ensure their validity.

The field work of the evaluation was developed between July 2011 and December 2012, one to three years after the installation of the systems, allowing enough time to analyse the autonomous functioning of the management model.

Table 2 summarises the field methodology employed:

\section{PLEASE INSERT TABLE 2}

Table 2. Description of the methodology employed

Table 3 presents the number of people who participated in the participatory workshops, focus groups, and individual interviews in each of the communities. A total of 161 users participated in this study, 90 men and 71 women. We also interviewed six members of the Practical Action technical team to understand the institutional vision regarding the management model in depth.

\section{PLEASE INSERT TABLE 3}

Table 3. Number of people who participated in the field research, disaggregated by gender

It should be noted that the methodology was specifically designed to analyse the possible gender inequalities that may exist. First, individual interviews were conducted with both men and women to understand the vision of both. Second, as in Cajamarca, women rarely actively participate in spaces where men are also involved; the participatory workshops, in which people actively expressed their opinions and debated based on their own world view, were performed with men and women separately. Finally, in the focus group with leaders, the facilitators strongly 
emphasised an investigation of women's ability to acquire positions of responsibility in the community and analysed their degree of participation in all project phases.

\section{Results}

To carry out the analysis, we focused on the three main phases of the implementation process of the management model: initial, developmental and operational phase. For each phase, several different indicators were defined, which are consistent with HD and useful in the analysis of each of the four dimensions previously described.

Table 4 presents the most relevant results from the fieldwork for the evaluation of the five projects, focusing on the three main phases of the implementation process of the management model. The last four columns in Table 4 also summarise the main relevant relationships for our analysis between the results of the indicators and each dimension. Next we present the most important issues that were analysed for each dimension.

- Equity and diversity: To analyse this dimension we focused particularly on the way vulnerable groups, especially women, are involved in the project, are free to participate in the process of the projects and have access to responsibility positions within the management model. These issues are mostly related to the indicators of initial and developmental phase, in which the process of the project requires participation of the entire population.

- Sustainability: In this case, we focused on how people are involved and motivated with the project, so that they will deeply adopt technology. Furthermore, quality of the service, appropriateness of operation and maintenance activities, skill improvement processes, non-payment rates and level of conflicts between inhabitants will be investigated to analyse technical, economical and organizational sustainability. These issues are mostly related to the indicators of the operational phase, in which the systems are already in use, but also to the indicators of the initial and developmental phases, in which involvement and motivation of the villagers are crucial for a sustainable project.

- Empowerment: In this analysis we investigated how power positions are managed during the projects, the quality of participation processes, and the ability this projects have had for people to be better organized to stand up for their rights and achieve their aims. These issues are mostly related to the indicators of the developmental phase, in which coordination between inhabitants and local organizations takes place to develop the project.

- Productivity: To analyse this dimension we focused on the ability for the technical solutions implemented to meet productive demands, on how businesses were created or 
improved with electricity, and on local innovations to take advantage of the resources. These issues are mostly related to the indicators of the initial phase, in which needs are defined, and the operational phase, in which productive use of energy can be assessed.

It should be noted that we are in a complex analytical framework where different indicators have influences on the different dimensions of HD. Moreover, the fieldwork methodology was defined to collect a vast amount of information among its different processes. World view, cultural values, traditions, personal feelings and opinions, etc. were analysed, and this information, which is difficult to reflect in indicators, will also be very important to carry out the discussion and come to conclusions. For that reason, the indicators of Table 4 should not be understood as those of a standard multi-criteria analysis, where indicators are pondered and a final score is obtained, but as a way to structure the analytical process. 
PLEASE INSERT TABLE 4

Table 4. Summary of the results from the fieldwork evaluation 


\section{Discussion and recommendations}

These results, which are based on the four pillars of the HD approach, will be discussed in more detail in the following sections, and strategies to be used in future projects to improve the impact on people's lives will be recommended.

\subsection{Equity and Diversity}

\subsubsection{Discussion}

PA tends to implement its management model in a standardised way in each community, which limits the ability to cope with the diversity found in each community. Not adapting the management model implies that PA believes that the rights and obligations of all the users are the same, without considering the possible needs of the most vulnerable groups. This attitude is evident, for example, in the community of Alto Peru, where an elderly family with three children with mental disabilities was unable to meet the obligations required to have electricity.

In all communities, PA has worked on the generation of knowledge, conducting training programs specifically designed for local operators, administrators, and users of the systems. While for some of the interviewees, these processes were successful, some weaknesses have been identified in terms of equity of access to these training sessions. First, operator and administrator training is held at CEDECAP in the city of Cajamarca, so villagers have to travel to the city, sometimes staying there several days. Attendees must be away from their livestock and fields, which represents an insurmountable barrier for many people. Such barriers to travel are particularly severe in the case of women, who are entirely responsible for their families' needs and are less able than men to leave home. As a result, many communities find no qualified women for the posts of operator and administrator.

User training was usually performed in assemblies in the communal centre or school. However, this method has shown some weaknesses. Users of the more remote households do not usually attend because of the distance. Furthermore, the people engaged in the training have differing levels of education, and many fail to understand some of the concepts. This issue is especially important for women and young people, because most of them are unable to attend the training sessions and, even if they can, their levels of assimilation of the concepts are usually low. This problem heightens the risk of the system being misused because the people at home who are most in contact with the equipment have the worst understanding. To overcome these weaknesses, in Alto Perú, the approach to user training was modified, and workshops for groups of households were held nearby at appropriate times to enable the participation of women and young people. With this improvement, the attendance of entire families significantly increased, and, with fewer users per session, it was easier to ensure that all participants understood the concepts.

\subsubsection{Recommendations}

To improve equity and diversity in future projects, we recommend using a more participatory diagnostic of the community to understand the reality of the population and its socioeconomic and cultural diversity. Therefore, it is necessary to emphasise qualitative information to provide information about cultural values and customs, analyse community organisations more deeply, and identify the barriers to active participation in the project 
that the most vulnerable sectors of the population may have. In particular, it is especially important to conduct a gender analysis, which is essential to defining proper strategies in the projects. To do this, various methods can be used, such as separating data by gender, having separate focus groups with men and women, ensuring that $50 \%$ of women are interviewed in this phase, analysing the roles and uses of time and analysing the strategic interests and practical needs of men and women.

Training processes oriented towards women as users, operators and mangers must be effective, allowing equitable access to and control of technology; thus, it is necessary to implement strategies and conduct training for men and women separately or in a decentralised manner (e.g., for groups of families, in areas close to their homes, and at times set by themselves), avoiding displacements outside the community.

\subsection{Sustainability}

\subsubsection{Discussion}

Only in Chorro Blanco and Suro Antivo did the initiative for electrification come from the community; in the other sites, PA proposed the implementation of an RE electrification project. In these latter cases, lower levels of involvement and motivation were found in comparison with the projects proposed by the community. This lower turnout caused lower levels of technology adoption, participation in meetings and training, and worse operation and maintenance by users. This set of weaknesses can increase the rate of breakdowns and nonpayments, thus affecting the sustainability of the systems.

Furthermore, none of the communities participated in the decision making about the design of the systems, which means that the systems do not always exactly meet the needs or wishes of families. Unsatisfied users often do not develop a sense of identification with technology. Their participation in meetings is weak, they are more likely to miss payments, and they do not perform the operation and maintenance tasks correctly. For example, we found that users at Campo Alegre are dissatisfied with their systems because DC cannot be used with many commercial appliances. In Alto Perú, wind and PV microgrid users would like to have individual systems.

In all the cases, people participated in the definition of user monthly tariffs. Although this tariff was based on the willingness to pay, it was insufficient to cover the costs of corrective maintenance and end-of-life equipment replacement. Therefore, it is vital to involve the municipality as the owner of the systems to ensure that it will provide a percentage of the total cost when needed. However, results show that the municipality does not participate in the monitoring and technical support of the systems. Furthermore, when allocating public funds, the municipality usually prioritises projects that provide political gain, not necessarily assisting those who need the most help. For this reason, when seeking municipal support, a community-based political campaign is needed.

Moreover, the quality of electrical power provided is not always the same for everyone and depends on both the technology and whether individual or microgrid systems are used. This issue could be controversial in projects where there is a diversity of systems, as in Alto Perú, where there could be a dilemma regarding the uniformity of tariffs. For example, the users of the microhydro system have a continuous service, whereas other users have a more limited service; however, the maintenance costs of the other systems are higher because of the costs of replacing batteries, inverters, or PV and wind regulators (the lifespans of which are much shorter than that of the equipment used in microhydro systems). Although some people prefer a differentiated tariff 
system, the vast majority of users interviewed claim to prefer a unified tariff system, in which the whole community has the same energy prices and the same tariff structure to avoid neighbourhood disputes. Although this type of situation could cause problems due to the socioeconomic diversity of the community, in the case of Alto Perú, the type of system installed and the economic level of households did not seem to influence the nonpayment rate.

As was explained before, many of the users interviewed did not clearly understand what was explained to them in the training sessions. This weakness becomes especially significant when individual systems, rather than microgrids, are installed in the community. The users of a microgrid are not responsible for the equipment because the system is centralised in one location and the operator ensures it is functioning correctly. In contrast, in individual PV or wind systems, the equipment is installed in households; therefore, the link between users and operation and maintenance tasks is stronger, and users are forced to strengthen their technical knowledge to minimise the risk of breakdowns. In fact, the analysed microgrid systems have proven to be more reliable and provide better quality service to users, especially the microhydro scheme, because operators can more easily perform operation and maintenance tasks in centralised systems (Millinger et al., 2012). A greater number of failures were found in individual systems, often due to a lack of user training, which increases operation and maintenance costs and reduces users' confidence in the systems and willingness to pay, ultimately reducing the sustainability of the systems.

Finally, in Andean rural areas, it is common to employ 'mitayos', as in the case of the five analysed communities. However, those who attend training sessions and meetings on the electrical system are often homeowners, who remain responsible for the equipment, even when they do not live there. Thus, in some households, the resident 'mitayos' may know nothing about the management model and have no basic knowledge about properly using the electrical equipment. It is also common for these residents to avoid their obligations, claiming that the responsibility lies with the owner, thereby increasing the likelihood of non-payment or damage and putting the sustainability of the systems at serious risk.

\subsubsection{Recommendations}

To improve sustainability in future projects, we recommend prioritising projects in which the initiative lies with the community, ensuring that electrification is a need felt by the population. If the project proposal comes from an institution, it will be necessary to emphasise community awareness about responsibility for the project and motivate future users to actively participate in the entire process, thus raising public awareness about the beneficial effects this will have on the level of technology adoption. With an actively involved and motivated population in the project, users adopt technology more deeply, thereby minimising the risk of system neglect or deterioration, which will have a positive effect in terms of sustainability. In addition, innovation should be promoted in the management model, the technology, and its use by local people so that the projects better meet their needs and local conditions and sustainability is maximised.

Moreover, public participation in the design of the systems and management model in each community must be encouraged, increasing the flexibility of the structure and regulations to adapt to local socioeconomic and cultural characteristics, thereby ensuring that technology meets the specific needs of each community.

Finally, training processes offered by operators and administrators should be imposed on new 'mitayos', and their participation in monthly meetings should be required so that they feel involved in system management 
and so that their level of technology adoption is improved.

\subsection{Empowerment}

\subsubsection{Discussion}

To improve people's participation in the project and promote users' identification with technology, PA requires involvement in infrastructure construction and equipment installation. However, different levels of involvement were observed in each community depending on the different characteristics of the systems. In particular, we found a strong difference between microhydro and individual PV and wind systems. Microhydro systems require high levels of organisation for a long period of time during the construction of the infrastructure. The process involves a routine of frequent community meetings and collaboration, which increases sense of community and strengthens the mechanisms for conflict resolution. This enhances a collective empowerment process within communities. By contrast, in the case of PV and/or wind systems, these processes do not require as much time or hard communal work. For example, we can compare the 50 working days provided by each user during the construction of the civil works in Suro Antivo, organised in rotating teams, against the few hours needed to install an individual PV system in homes in Alto Perú, where neighbours did not support each other.

However, it was observed that in all cases, the level of involvement of women in the construction and installation phase was very different from that of men, with women's role mainly limited to the preparation of food for working men, thereby being less involved in the coordination meetings throughout the installation of the systems. As a result, their level of identification with technology and collective empowerment were not improved to the same extent as men. Furthermore, inequalities in terms of the position of women relative to men place women in a situation of inferiority that restricts their right to free and active participation in learning and decision-making processes. In fact, it was found that most of the time, when women attend meetings, their role is limited to listening because they do not feel confident enough to actively participate in decision making. However, the management model does not include any specific strategy to address these problems, which severely limits the impact of the project in terms of empowerment of women.

Only in Suro Antivo were profound changes observed in terms of collective empowerment. The fact that the project was conducted with the active participation of everyone provided the population with confidence to mobilise and attempt to obtain new projects. This process is intimately linked to the empowerment of the leader of the community throughout the process of the project, who has led his community to demand greater investment by the municipality. In fact, the community has already managed to accomplish projects to replace wooden poles for power lines with concrete poles and to improve the microhydro water channel; they are now mobilising for a new sanitation project. However, in the other communities, no significant changes in this regard have been observed, which shows that such projects do not promote empowerment by themselves.

In addition, it was found that the training processes are excessively technical, not focusing on the establishment of a community-wide development process but on the technical sustainability of the systems, which may be one of the reasons why the empowerment levels attained by the population were low.

\subsubsection{Recommendations}

To promote the empowerment of people, it is necessary to create inclusive spaces for decision making that ensure a high degree of community involvement in all project phases. Hence, to improve the impact in terms of 
empowerment in future development projects, we recommend that the institution responsible facilitates a process led by the people themselves, designing specific strategies so as to produce a more profound change in people's lives and influence them politically to stand up for their rights. To accomplish this task, leaders could be trained in community management, human rights, environmental protection, project management, and the Public Investment National System ${ }^{2}$. The generation and strengthening of these capacities can encourage changes in the power structures in favour of the most vulnerable. Furthermore, the design of training courses must take into account needs and constraints from every section of the population (men, women, young people, elderly, etc.). At this point, women deserve particular consideration as an especially vulnerable sector, so specific workshops should be included to strengthen women's organisations; furthermore, training should be offered that meets the specific strategic interests of women identified in the gender diagnosis, strengthening their self-esteem and improving their capabilities to argue and speak publicly to improve their willingness to actively participate in meetings and decision-making processes.

\subsection{Productivity}

\subsubsection{Discussion}

Because the management model was designed by PA, with a very low participation rate, many of those interviewed affirmed that they did not know how the model works, which has limited the ability of people to make innovations and improvements to this model. In fact, only one innovation has been identified in the community of Campo Alegre, where reserve funds from tariffs are used as a revolving fund, with responsibility for monitoring the return given to the control unit. Thus, the community itself promotes access to credit for generating small businesses and boosting productivity.

In the case of Campo Alegre and Alto Perú, the systems were designed to meet only domestic needs, and the generation of businesses was not considered. Thus, although some productive initiatives appear in some communities, the installed systems are not able to meet this type of demand, severely limiting the impact of these projects in terms of productivity (Bhattacharyya, 2012). For instance, one of the users of an individual PV system in Alto Perú has a small cheese production factory, but he can only improve it with electrical power by extending working hours when necessary, which is just an indirect productivity improvement (Bhattacharyya, 2006).

At the same time, in some communities, such as Suro Antivo, where the system supplies enough energy, people hope to start new businesses, yet not one business has been created due to a lack of specific training during project implementation. Only small grocery stores use the lighting to stay open at night, which means that projects are not encouraging new businesses.

\subsubsection{Recommendations}

As access to electricity does not promote productivity by itself, specific strategies are needed to encourage the creation of new businesses. To do so, training plans on production, business management and market access must be developed, in addition to the development of tools to improve access to credit and the community helping to create associative or cooperative businesses. In particular, by establishing quality participation

\footnotetext{
${ }^{2}$ An administrative system that controls the efficiency, sustainability and socioeconomic impact of public projects
} 
processes, community organisations are strengthened, enabling them to develop new productive projects collectively, because there are many barriers that must be overcome to generate rural enterprises individually.

\section{Conclusions}

In this paper, we have used the HD approach to analyse the management model of five rural RE electrification projects in Cajamarca, Peru. We aimed to identify weaknesses that are not normally considered in conventional evaluations of such systems. This approach broadens the base of information with which to analyse technological projects, focusing not only on the resources generated but also on the expansion of opportunities for people. Thanks to the application of this approach and using an innovative methodology, some barriers have been found that this type of project must overcome, which, to date, have not been addressed.

In technological terms, we cannot affirm from this investigation that any of the technologies is more recommendable than others in Andean rural areas. While microhydro systems are commonly preferred, we have seen that PV and wind systems can also be effective in rural communities, depending on resource availability. In fact, regarding the results of this analysis, we can state that all the technologies analysed in this paper might have a great impact in terms of Human Development, but success strongly depends on the process of implementing the management model.

Indeed, access to electricity has positive effects in terms of improved living conditions, but electrical power cannot profoundly transform the lives of a population, especially the most vulnerable, by itself. Actually, a good development of the process of implementing the management model is an opportunity to improve the project's ability to transform people's lives. However, we have found that, in general, insufficient emphasis is given to this process, potentially resulting in low levels of technology adoption for much of the population, the entrenchment of social inequalities, low levels of productivity increase, the entrenchment of unequal power structures, and, in general, only insignificant increases in the ability of people to stand up for their rights against local governments.

In this paper, we have presented a number of recommendations by which the management model can overcome these barriers, which, by conventional analysis, would not have been identified, improving the opportunity for electrification in Peruvian rural areas to act as a catalyst for development.

First, to improve the impact on equity and diversity, qualitative tools should be employed in the identification phase to provide information regarding cultural values and customs and special barriers that must be overcome by the most vulnerable sections of the population, especially women, before they can participate actively in the project. In addition, all the population should be involved in the design process of the management model, thereby ensuring the project considers the specific needs of all families, including the most vulnerable.

Second, to improve sustainability in future projects, we recommend prioritising projects where the initiative comes from the community. With an involved and motivated population, higher levels of technology adoption are acquired, and the risk of system deterioration is reduced. In particular, special efforts are needed to guarantee the involvement of the 'mitayos' in systems management.

Third, concerning empowerment, training plans and courses must take into account needs and specific 
constraints from every sector of society because capacity building is a key tool for promoting changes in power structures. Moreover, to promote empowerment, the management model must consider inclusive spaces for decision making, ensuring a high degree of participation.

Fourth, to encourage productivity, it is necessary to develop training plans on production, business management, and access to markets as well as implement tools to improve access to credit and strengthen community organisations to create associative or cooperative businesses.

Although most of the recommendations will increase the costs of these kind of projects in rural areas slightly, their consideration within the processes of the projects will strongly increase the impact on people's lives. For that reason, these small extra costs are considered minimal in comparison with the huge improvements and focusing on these recommendations in future plans and strategies is strongly recommended.

\section{References}

Akorede, M.F., Hizam, H. and Pouresmaeil E., 2010. Distributed energy resources and benefits to the environment. Renewable and Sustainable Energy Reviews 14 724-734.

Benecke, G., 2008. Success factors for the effective implementation of renewable energy options for rural electrification in India - Potentials of the clean development mechanism. International Journal of Energy Research 32:1066-1079.

Bhattacharyya, S.C., 2006. Renewable energies and the poor: niche or nexus? Energy Policy 34 659-663.

Bhattacharyya, S.C., 2012. Energy access programmes and sustainable development: A critical review and analysis. Energy for Sustainable Development, 16:260-271.

Borges, K., Walter, A. and Rei, F., 2007. CDM implementation in Brazil's rural and isolated regions: the Amazonian case. Climatic Change, Volume 84, Issue 1, pp 111-129.

Breyer, Ch., Gerlach, A., Hlusiak, M., Peters, C., Adelmann, P., Winiecki, J., Schützeichel, H., Tsegaye, S. and Gashie, W, 2009. Electrifying the poor: Highly economic off-grid PV systems in Ethiopia - A basis for sustainable rural development. 24th European Photovoltaic Solar Energy Conference.

Bugaje, I.M., 2006. Renewable energy for sustainable development in Africa: a review. Renewable and Sustainable Energy Reviews, Volume 10, Issue 6, pp 603-612.

Chaurey A, Ranganathana, M. and Mohanty, P., 2004. Electricity access for geographically disadvantaged rural communities - technology and policy insights. Energy Policy 32 1693-1705.

Chaurey, A., Kandpal, T.C., 2010a. Assessment and evaluation of PV based decentralized rural electrification: an overview. Renewable and Sustainable Energy Reviews, 14:2266-2278.

Chaurey, A., Kandpal, T.C., 2010b. A techno-economic comparison of rural electrification based on solar home systems and PV microgrids. Energy Policy, 38:3118-29. 
Coello, J., Escobar, R., Dávila, C., Villanueva, G., Chiroque, J., 2006. Micro hydro power plants and other alternative energies: contributions of Practical Action - ITDG to rural development. Environmental case studies and white/technical papers. Port of Entry, Environmental Business Network for the Americas.

Cook, C.C., Duncan, T., Jitsuchon, S., Sharma, A., Guobao, W., 2005. Assessing the impact of transport and energy infrastructure on poverty reduction. Manila: Asian Development Bank.

Dong, A., 2008. The policy of design: A capabilities approach. Design Issues, 24(4), pp. 76-87.

Drinkwaard, W., Kirkels, A., Romijn, H., 2010. A learning-based approach to understanding success in rural electrification: Insights from Micro Hydro projects in Bolivia. Energy for Sustainable Development, 14:232-237.

Energy Sector Management Programme (ESMAP), 2001. Peru: Rural electrification.

Escobar, R; Vilar, D; Velo, E; Ferrer-Martí, L; Domenech, B (2012) Promoting and Improving Renewable Energy Projects Through Local Capacity Development, in Modeling and Optimization of Renewable Energy Systems, (ISBN: 978-953-51-0600-5), In-Tech, 147-170.

Fernández-Baldor, Á., Hueso A., and Boni A., 2012. 'From Individuality to Collectivity: The Challenges for Technology-Oriented Development Projects', in I. Oosterlaken and J. Van der Hoven (Eds), The Capability Approach, Technology and Design, Springer, Dordrecht, pp. 223-244.

Ferrer-Martí, L., Garwood, A., Chiroque, J., Escobar, R., Coello, J. and Castro, M., 2010. A community small-scale wind generation project in Peru. Wind Engineering, 34:277-288.

Ferrer-Martí, L., Garwood, A., Chiroque, J., Ramirez, B., Marcelo, O., Garfi, M. and Velo, E., 2012. Evaluating and comparing three community small-scale wind electrification projects. Renewable and Sustainable Energy Reviews, 16:5379-5390.

Gomez, M. and Silveira, S., 2010. Rural electrification of the Brazilian Amazon - achievements and lessons. Energy Policy, 38:6251-6260.

Gouvello, C., 2002. The limitations of the conventional grid: Bank on complementarity. Decentralised Rural Electrification: An Opportunity for Mankind, Technique for the Planet, pages 127-138.

Groh, S., 2014. The role of energy in development processes-The energy poverty penalty: Case study of Arequipa (Peru). Energy for Sustainable Development, 18:83-99.

Hiremath, R., Kumar, B., Balachandra, P., Ravindranath, N.H. and Raghunandan, B., 2009. Decentralised renewable energy: Scope, relevance and applications in the Indian context. Energy for Sustainable Development, 13:4-10.

Jacobson, A., 2007. Connective Power: Solar Electrification and Social Change in Kenya. World Development, 35$1: 144-162$

Kaundinya, D., Balachandra, P. and Ravindranath, N.H., 2009. Grid-connected versus stand-alone energy systems 
for decentralized power-a review of literature. Renewable and Sustainable Energy Reviews, 13:2041-2050.

Kaygusuz, K., 2011. Energy services and energy poverty for sustainable rural development. Renewable and Sustainable Energy Reviews, 15:936-947.

Khan, M., Iqbal, M., 2005. Pre-feasibility study of stand-alone hybrid energy systems for applications in Newfoundland. Renewable Energy 30(6):835-54.

Kooijman-van Dijk, A., Clancy, J., 2010. Impacts of Electricity Access to Rural Enterprises in Bolivia, Tanzania and Vietnam. Energy for Sustainable Development, 14:14-21.

Leary, J., While, A., Howell, R., 2012. Locally manufactured wind power technology for sustainable rural electrification. Energy Policy, 43:173-183.

Lhendup, T., 2008. Rural electrification in Bhutan and a methodology for evaluation of distributed generation system as an alternative option for rural electrification. Energy for Sustainable Development, 12:13-24.

Millinger, M., Marlind, T., Ahlgren, E.O., 2012. Evaluation of Indian rural solar electrification: A case study in Chhattisgarh. Energy for Sustainable Development, 16:486-492.

Nerini, F.F., Howells, M., Bazilian, M., Gomez, M.F., 2014. Rural electrification options in the Brazilian Amazon. A multi-criteria analysis. Energy for Sustainable Development, 20:36-48.

Nguyen, K., 2007. Alternatives to grid extension for rural electrification: Decentralized renewable energy technologies in Vietnam. Energy Policy, 35:2579-2589.

Oosterlaken, I., Grimshaw D., Janssen P., 2012. 'Marrying the capability approach with appropriate technology and STS - The case of podcasting devices in Zimbabwe', in I. Oosterlaken and J. Van der Hoven (Eds), The Capability Approach, Technology and Design, Springer, Dordrecht, pp. 113-133.

Oosterlaken, I., 2009. 'Design for Development; A Capability Approach', Design Issues, 25(4) pp. 91-102.

Palit, D., 2013. Solar energy programs for rural electrification: Experiences and lessons from South Asia. Energy for Sustainable Development, 17:270-279.

Pasternak, A., 2000. Global energy futures and human development: a framework for analysis. Lawrence Livemore National Library.

REN21, 2008. Renewables 2007-Global Status Report. Washington, D.C Renewable Energy Policy Network for the 21st Century.

Sen, A., 1999. Development as freedom. Oxford University Press.

Sánchez, T., 2006. Key factors for the implementation of successful, stand-alone village electrification schemes. PhD Thesis.

Sánchez, T., Williams, A. and Smith, N. 2006. The critical factors for success of stand-alone energy schemes. 
International Conference on Renewable Energy for Developing Countries.

Shyu, C., 2013. End-users' experiences with electricity supply from stand-alone mini-grid solar PV power stations in rural areas of western China. Energy for Sustainable Development, 17:270-279.

Shyu, C., 2014. Ensuring access to electricity and minimum basic electricity needs as a goal for the post-MDG development agenda after 2015. Energy for Sustainable Development, 19:29-38.

ul Haq, M. 1995. Reflections on Human Development. Oxford University Press.

Valer, L.R., Mocelin, A., Zilles, R., Moura, E., Nascimento, C.S., 2014. Assessment of socioeconomic impacts of access to electricity in Brazilian Amazon: case study in two communities in Mamirauá Reserve. Energy for Sustainable Development, 20:58-65.

van Els, R.H., Souza, J.N., Pinho, J.C., 2012. The Brazilian experience of rural electrification in the Amazon with decentralized generation - The need to change the paradigm from electrification to development. Renewable and Sustainable Energy Reviews, 16:1450-1461.

Williams, A.A., Simpson, R., 2009. Pico hydro - Reducing technical risks for rural electrification. Renewable Energy, 34:1986-1991.

Yadoo, A. and Cruickshank, H., 2010. The value of cooperatives in rural electrification. Energy Policy, 38:29412947.

Yadoo, A. and Cruickshank, H., 2012. The role for low carbon electrification technologies in poverty reduction and climate change strategies: A focus on renewable energy mini-grids with case studies in Nepal, Peru and Kenya. Energy Policy, 42:591-602. 


\section{Highlights}

Management models for off-grid renewable energy systems are analysed.

Five projects in Peru are evaluated using the Human Development approach.

Equity and diversity, sustainability, empowerment and productivity are analysed.

New barriers that may limit the impact of the projects are identified.

Several recommendations are proposed to overcome these barriers. 


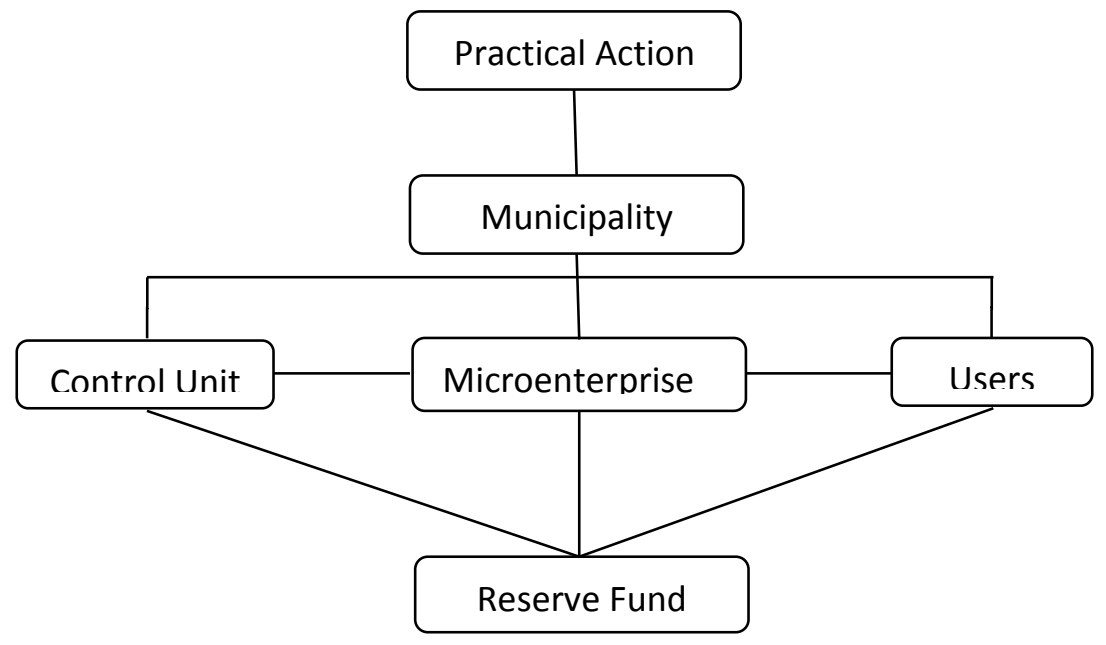

Figure 1. General scheme of the Practical Action management model. Adapted from Ferrer-Martí et al. 2010.
Practical Action: Implements the project

Municipality: Legal owner of the systems

Microenterprise: Operates and manages the systems

Users: Pay a monthly tariff

Control unit: supervises the microenterprise and users, and solves conflicts

Reserve fund: Comes from the tariff collection 


\begin{tabular}{|c|c|c|c|c|c|c|c|}
\hline Community & Technology & DC/AC & $\begin{array}{c}\text { Number } \\
\text { of } \\
\text { operators }\end{array}$ & $\begin{array}{c}\text { Number of } \\
\text { administrators }\end{array}$ & $\begin{array}{c}\text { Monthly } \\
\text { tariff } \\
\text { baseline (NS) }\end{array}$ & $\begin{array}{c}\text { Beneficiary } \\
\text { families }\end{array}$ & $\begin{array}{c}\text { Project Finish } \\
\text { Date }\end{array}$ \\
\hline Alto Perú & $\begin{array}{c}\text { - Wind microgrid } \\
- \text { PV microgrid } \\
- \text { - Microhydro } \\
- \text { Individual PV }\end{array}$ & AC & 3 & 1 & 13 & 51 & $\begin{array}{c}\text { June-09 (1st } \\
\text { phase) } \\
\text { Sept-10 (2nd } \\
\text { phase) }\end{array}$ \\
\hline Suro Antivo & Microhydro & AC & 2 & 1 & 10 & 60 & $\begin{array}{c}\text { Oct-10 (1st } \\
\text { phase), Aug-2012 } \\
\text { (2nd phase) }\end{array}$ \\
\hline $\begin{array}{c}\text { Chorro } \\
\text { Blanco }\end{array}$ & Microhydro & AC & 1 & 1 & 10 & 37 & May-10 \\
\hline $\begin{array}{c}\text { Campo } \\
\text { Alegre }\end{array}$ & $\begin{array}{c}\text { Individual hybrid } \\
\text { wind and PV }\end{array}$ & DC & 1 & 1 & 14 & 20 & May-08 \\
\hline El Regalado & Microhydro & AC & 1 & 1 & 10 & 31 & Dec-09 \\
\hline
\end{tabular}

Table 1. Comparison of analysed projects

\begin{tabular}{|l|l|}
\hline \multicolumn{1}{|c|}{ Methodology } & \multicolumn{1}{c|}{ Information to be obtained } \\
\hline Participant observation & $\begin{array}{l}\text { Organizational level of the population, motivation, and } \\
\text { involvement of users }\end{array}$ \\
\hline $\begin{array}{l}\text { Focus group with leaders and } \\
\text { authorities }\end{array}$ & $\begin{array}{l}\text { Initiative of the project, community participation in the } \\
\text { different phases of the project, user motivation and } \\
\text { involvement, technical role of PA and technology transfer } \\
\text { process, processes of empowerment. }\end{array}$ \\
\hline $\begin{array}{l}\text { Participatory workshops with men } \\
\text { and women separately }\end{array}$ & Project impacts on lives \\
\hline $\begin{array}{l}\text { Individual interviews with users, } \\
\text { operators, administrators, leaders } \\
\text { and members of the control unit }\end{array}$ & $\begin{array}{l}\text { Establishing how that person has participated throughout } \\
\text { the project (training, meetings, etc.), and discovering the } \\
\text { level of knowledge about the systems and the management } \\
\text { model }\end{array}$ \\
\hline
\end{tabular}

Table 2. Description of the methodology employed

\begin{tabular}{|c|c|c|c|c|c|c|}
\cline { 2 - 7 } \multicolumn{1}{c|}{} & \multicolumn{2}{c|}{ Focus group with leaders } & \multicolumn{2}{c|}{ Participatory workshops } & \multicolumn{2}{c|}{ Individual interviews } \\
\cline { 2 - 7 } \multicolumn{1}{c|}{} & Men & Women & Men & Women & Men & Women \\
\hline Alto Perú & 4 & 4 & - & 5 & 13 & 4 \\
\hline Suro Antivo & 2 & 1 & - & - & 6 & 3 \\
\hline Chorro Blanco & 7 & 1 & 8 & 15 & 9 & 9 \\
\hline Campo Alegre & 4 & 1 & 20 & 7 & 5 & 6 \\
\hline El Regalado & - & - & 10 & 10 & 2 & 5 \\
\hline
\end{tabular}

Table 3. Number of people who participated in the field research, disaggregated by gender 


\begin{tabular}{|c|c|c|c|c|c|c|c|c|c|c|}
\hline & & \multicolumn{5}{|c|}{ Results } & \multicolumn{4}{|c|}{ Analysis } \\
\hline $\begin{array}{l}\text { Phases of the } \\
\text { management } \\
\text { model } \\
\text { implementation } \\
\text { process }\end{array}$ & Indicators & Alto Perú & Suro Antivo & $\begin{array}{l}\text { Chorro } \\
\text { Blanco }\end{array}$ & $\begin{array}{l}\text { Campo } \\
\text { Alegre }\end{array}$ & El Regalado & 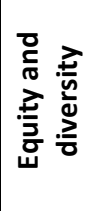 & 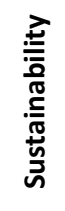 & 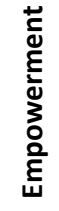 & 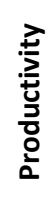 \\
\hline \multirow{6}{*}{ Initial phase } & Project initiative & PA & Community & Community & $\mathrm{PA}$ & PA & & $\mathrm{x}$ & & \\
\hline & Public participation in technical design of project & \multicolumn{5}{|c|}{ No } & $\mathrm{X}$ & & & $\mathrm{X}$ \\
\hline & Public participation in design of management model & \multicolumn{5}{|c|}{ Only in the definition of the tariff } & $\mathrm{X}$ & & & $\mathrm{X}$ \\
\hline & Male participation in meetings & Low & High & High & Medium & Medium & $\mathrm{X}$ & $\mathrm{X}$ & & \\
\hline & Participation of women and youth in meetings & \multicolumn{5}{|c|}{$\begin{array}{l}\text { Low. Generally family representation lies with the male, so the other members } \\
\text { of the family do not usually participate to the same extent. In addition, their } \\
\text { participation is usually passive, normally limited to listening. }\end{array}$} & $\mathrm{x}$ & $x$ & & \\
\hline & $\begin{array}{l}\text { Mechanisms implemented in the design to cater specifically to the most } \\
\text { vulnerable }\end{array}$ & \multicolumn{5}{|c|}{ No } & $\mathrm{x}$ & & & \\
\hline \multirow{7}{*}{$\begin{array}{l}\text { Development } \\
\text { phase }\end{array}$} & Working days in the construction and installation of systems per user & 1 (PV) 15 (others) & 50 & 50 & 1 & 55 & & & $\mathrm{x}$ & \\
\hline & Involvement of women in the installation of systems & $\begin{array}{c}\text { Only in the Microhydro } \\
\text { system, cooking for } \\
\text { male workers }\end{array}$ & $\begin{array}{c}\text { Cooking for } \\
\text { male } \\
\text { workers }\end{array}$ & $\begin{array}{c}\begin{array}{c}\text { Cooking for } \\
\text { male } \\
\text { workers }\end{array} \\
\end{array}$ & No & $\begin{array}{l}\text { Cooking for } \\
\text { male workers }\end{array}$ & $\mathrm{x}$ & & $\mathrm{x}$ & \\
\hline & Motivation of the population & Low & High & High & Medium & Medium & & $\mathrm{X}$ & & \\
\hline & Male participation in training for users & \multicolumn{5}{|c|}{$\begin{array}{l}\text { Strongly depends on the level of motivation, as well as the distance to the } \\
\text { centre from the household where trainings are conducted }\end{array}$} & $\mathrm{x}$ & & $x$ & \\
\hline & Participation of women and youth in training for users & \multicolumn{5}{|c|}{$\begin{array}{l}\text { Low. Generally family representation lies with the male, so the other members } \\
\text { of the family do not usually participate to the same extent. In addition, their } \\
\text { participation is usually passive, normally limited normally to listening. }\end{array}$} & $\mathrm{x}$ & & $\mathrm{x}$ & \\
\hline & Male participation in operator and administrator training & \multicolumn{5}{|c|}{$\begin{array}{l}\text { High, but restricted to those users who can stay at CEDECAP (Cajamarca) for } \\
\text { more than one day }\end{array}$} & $x$ & & $x$ & \\
\hline & Participation of women in the operator and administrator training & \multicolumn{5}{|c|}{$\begin{array}{l}\text { No. Women do not have the same freedom as men to leave their home for } \\
\text { several days, as they are responsible for family care. }\end{array}$} & $x$ & & $x$ & \\
\hline \multirow{10}{*}{$\begin{array}{l}\text { Operational } \\
\text { phase }\end{array}$} & Non-payment rate & Medium & Low & Low & Low & Low & & $\mathrm{x}$ & & \\
\hline & Houses inhabited by 'mitayos' & & & Yes & & & & $\mathrm{x}$ & & \\
\hline & Quality of operation and maintenance in households & Low & High & High & Medium & High & & $\mathrm{x}$ & & \\
\hline & $\begin{array}{l}\text { Quality of operation and maintenance in households inhabited by } \\
\text { 'mitayos' }\end{array}$ & \multicolumn{5}{|c|}{ Low } & & $x$ & & \\
\hline & Quality of service (lack of disruptions) & Low & High & High & Medium & High & & $\mathrm{x}$ & & \\
\hline & Level of conflicts & High & Low & Low & Medium & Low & & $\mathrm{X}$ & & \\
\hline & Created or improved businesses & One grocery store & $\begin{array}{c}\text { One grocery } \\
\text { store }\end{array}$ & 0 & 0 & $\begin{array}{c}\text { Two grocery } \\
\text { stores }\end{array}$ & & & & $\mathrm{x}$ \\
\hline & Municipality participation in monitoring and technical assistance & \multicolumn{5}{|c|}{ No } & & & $\mathrm{X}$ & \\
\hline & Community innovations to the management model & No & No & No & $\begin{array}{l}\text { The } \\
\text { reserve } \\
\text { fund is } \\
\text { used as a } \\
\text { revolving } \\
\text { fund }\end{array}$ & No & & & & $\mathrm{x}$ \\
\hline & New projects carried out by the community & No & Yes & No & No & No & & & $\mathrm{x}$ & \\
\hline
\end{tabular}

Table 4. Summary of the results from the fieldwork evaluation 
